\title{
Abnormal umbilical artery Doppler velocimetry and placental histopathological correlation in fetal growth restriction
}

\author{
R Agarwal, ${ }^{1} \mathrm{MS}(\mathrm{O} \& \mathrm{G}) ;$ A Tiwari, ${ }^{1} \mathrm{MBBS} ; \mathbf{N}$ Wadhwa, ${ }^{2} \mathrm{MD}$ (Pathology); G Radhakrishnan, ${ }^{1} \mathrm{MS}$ (O\&G); \\ S Bhatt, ${ }^{3} \mathrm{MD}$ (Radiology); P Batra, ${ }^{4} \mathrm{MD}$ (Paediatrics) \\ ${ }^{1}$ Department of Obstetrics and Gynaecology, University College of Medical Sciences and Guru Teg Bahadur Hospital, Delhi, India \\ ${ }^{2}$ Department of Pathology, University College of Medical Sciences and Guru Teg Bahadur Hospital, Delhi, India \\ ${ }^{3}$ Department of Radiology, University College of Medical Sciences and Guru Teg Bahadur Hospital, Delhi, India \\ ${ }^{4}$ Department of Paediatrics, University College of Medical Sciences and Guru Teg Bahadur Hospital, Delhi, India
}

Corresponding author: R Agarwal (rachna_anila@yahoo.co.in)

Background. Doppler velocimetry (DV) is widely used to assess the vascular formation of the placenta in fetal growth restriction (FGR) and to estimate the haemodynamic condition of the growth-restricted fetus. Umbilical artery (UA) flow is essentially placental, rather than fetal. Hence, DV provides information about the fetal side of the placenta and, alongside placental histopathology, it could possibly help to decipher aetiopathogenesis in FGR cases.

Objective. To correlate UA DV findings occurring in FGR with placental findings.

Methods. The study was prospective and conducted in a low-income setting. A total of 130 non-anomalous singleton FGR pregnancies ( $\geq 24$ weeks) were included in the study. All pregnancies were confirmed to be small for gestational age (SGA) after the birth of the neonate. The placental lesions and neonatal outcomes were correlated with DV findings before delivery: 65 cases with normal DV results constituted group 1, and group 2 had 65 cases with abnormal DV results such as reduced flow, absent UA end diastolic flow or reversal of UA end diastolic flow.

Results. Group 2 had significantly lower mean (standard deviation) birth weights of $1.59(0.4) \mathrm{kg}$ v. $1.87(0.23) \mathrm{kg}$ for group 1 ( $p<0.001)$. Considerably higher NICU mortality was seen in group $2(30.5 \%)$ compared with group $1(6.7 \%)(p<0.001)$. The group 2 placentas weighed less, had a higher number of maternal underperfusion (MUP) lesions, higher levels of calcification. Among lesions of MUP, 4 lesions i.e. villous infarction $(p<0.001)$, villous agglutination $(p<0.001)$, syncytial knots $(p=0.003)$ and intervillous fibrin deposition $(p=0.001)$ were present in significantly higher numbers in the abnormal Doppler group compared with the normal Doppler group. Abnormal Doppler had a sensitivity of $80 \%$ and specificity of $92.3 \%$ for abnormal placental pathology (placental lesions $\geq 3$ ).

Conclusions. There was a significantly higher number of MUP lesions and neonatal morbidity in SGA patients with abnormal DV findings.

S Afr J Obstet Gynaecol 2017;23(1):12-16. DOI:10.7196/SAJOG.2017.v23i1.1109

Fetal development is very closely related to placental development. Primary villus maldevelopment with evidence of reduced placental villus stem arteries and small, fibrotic, hypovascular terminal villi, have been shown in various pathological studies of the placenta of pregnancies complicated by fetal growth restriction (FGR)..$^{[-5]}$ Clinically, many abnormal umbilical artery (UA) waveforms are associated with these pathological findings such as increased Doppler resistance, reduced flow, absent UA end diastolic flow (AEDF) or reversal of UA end diastolic flow (REDF) flow. ${ }^{[4]}$ However, the true clinical implications of these placental findings and Doppler velocimetry (DV) associations are still not well established. ${ }^{[6]}$

We determined whether the abnormal UA DV occurring in FGR patients when correlated with the placental findings could possibly give insight into the aetiopathogenesis of FGR and guide towards early treatment and better neonatal outcomes using DV as a tool.

\section{Methods}

The study was conducted in a low-income setting between 2014 and 2016. Prior ethical committee clearance (IEC-UCMS dated 30 October 2014) and patient consent were obtained for the study.
The inclusion criteria for the study was a singleton pregnancy at $\leq 24$ weeks of gestation suspected of having FGR (sonographically estimated fetal weight $<10$ th percentile for the gestational age). All these cases were confirmed postnatally as small for gestational age (SGA). SGA was defined as actual birth weight $<10$ th percentile for that gestational age. ${ }^{[7,8]}$ Pregnancies with an anomalous fetus or associated with any known maternal diseases were excluded.

A standard protocol was followed to determine UA Doppler indices for all patients. Ultrasound was performed using a convex transducer at a frequency $3.5-5 \mathrm{MHz}$. The free-floating loop of the umbilical cord was selected for investigation. The angle of insonation was always kept lower than $30^{\circ}$. The pulsatility index (PI) of the UA was determined and any absence or REDF in the UA was also recorded.

The patients were divided into two groups based on UA Doppler indices at delivery:

Group 1: Normal DV findings (based on PI) in FGR subjects

Group 2: Abnormal DV findings (based on PI >95th percentile and/or absent or reversed end diastolic flow) in FGR subjects.

The study methodology is detailed in Fig 1. Stained histopathological slides were evaluated by a trained pathologist who was blind to 
both the clinical and imaging results. Histological lesions were broadly defined according to the nomenclature and the diagnostic criteria proposed by the placental classification provided by Redline. ${ }^{[9]}$ The discrete histopathological findings were grouped into 15 main findings and four major pathological patterns for the purpose of statistical analysis: ${ }^{[10]}$ (i) maternal vascular underperfusion (MUP) including non-marginal, recent, and organised infarction involving $>10 \%$ of parenchyma, agglutination, placental syncytial (ST) knots, intervillous fibrin deposition involving more than $20 \%$ of the intervillous space, peri-villous fibrin deposition, villous hypoplasia, intervillous haematoma or retroplacental haematoma; (ii) fetal vascular underperfusion (FUP) including fetal vasculopathy and/or avascular villi; (iii) inflammatory with villitis, chorioamnionitis or vasculitis lesions; (iv) others (stromal fibrosis and calcification). The placental lesions were then compared with DV findings (at delivery) and prospectively with neonatal outcome.

\section{Statistical analysis}

Statistical software SPSS version 20.0 (IBM Corp., USA) was used for statistical analysis. Upon histopathological examination, six placental lesions (villous infarction, agglutination, syncytial knots, intervillous fibrin deposition, stromal fibrosis, calcification) were

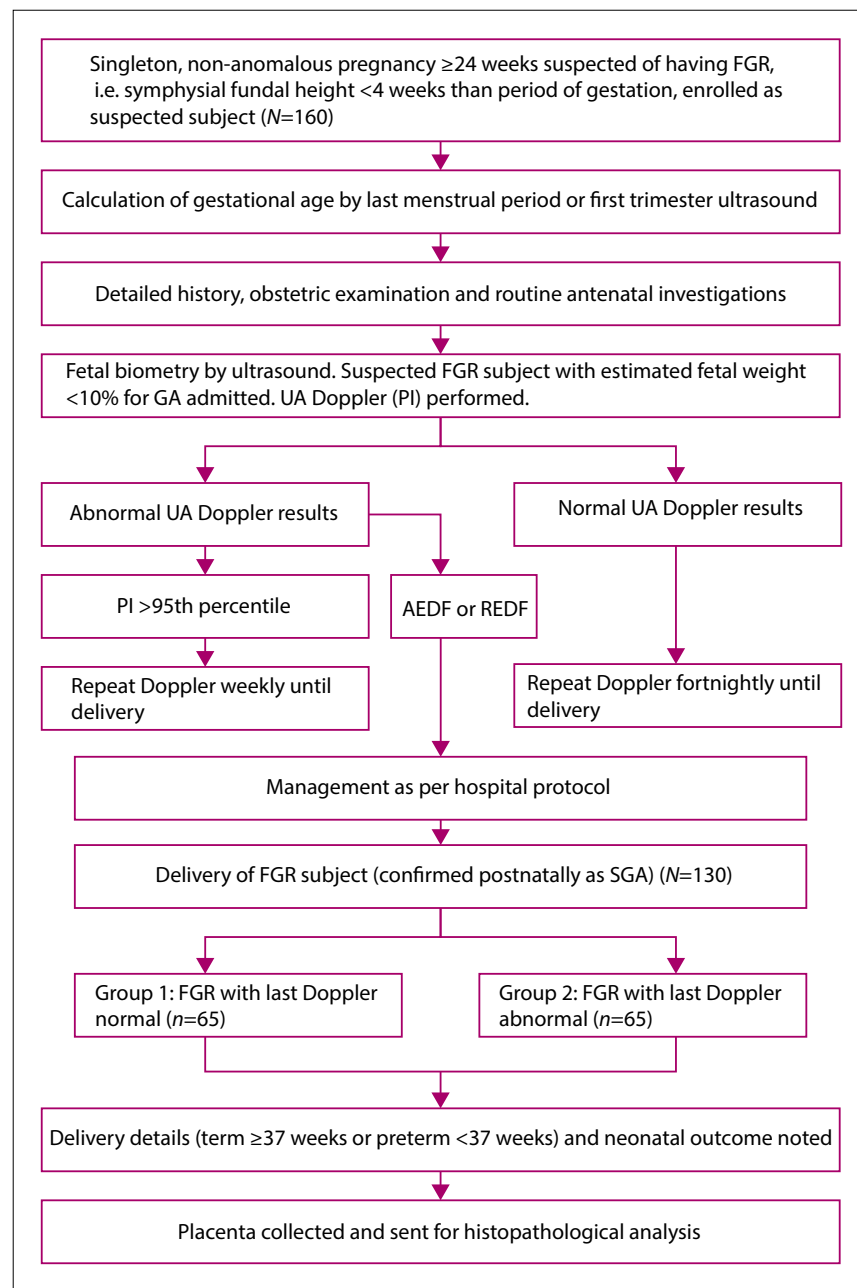

Fig 1. Flow diagram depicting study methodology. ( ${ }^{*}$ Thirty subjects were excluded because of unconfirmed SGA based on antenatal ultrasound biometry $(\mathrm{n}=8)$, unconfirmed SGA postnatally $(\mathrm{n}=6)$, inability to collect placental tissue $(\mathrm{n}=10)$, and some cases were lost to follow- $\mathrm{up}(\mathrm{n}=6)$. found to present in a significantly higher number in group 2 . Taking these six lesions into consideration, a receiver operating characteristic (ROC) curve was drawn. The optimal threshold point for the lesions ( $\geq 3$ placental lesions; classified as abnormal placental pathology) was obtained where the sum of sensitivity and specificity was at a maximum (Youden Index) and the best cut-off point was found. This was further used to calculate the screening potential of UA indices.

\section{Results}

Both groups were comparable in terms of age, parity and body mass index characteristics (Table 1). In fetal biometry, the mean (SD) biparietal diameter (group 1: 35.69 (1.93) weeks; group 2: 35.19 (3.32) weeks), mean (SD) femur length (group 1: 34.09 (2.10) weeks; group 2: 33.19 (2.75) weeks and mean (SD) amniotic fluid index (group 1: $6.9(3.41) \mathrm{cm}$; group 2: $7.6(4.33) \mathrm{cm}$ ) were nearly same for both groups. There was a significant difference in fetal abdominal circumference and estimated fetal weight between the two groups (Table 1). The findings of the last UA Doppler at delivery showed that all the patients in group 2 had UA PI $>95$ th percentile for their gestation period, 36 had only raised PI, 16 had AEDF, and 13 had REDF. The mean (SD) PI of group 2 was 1.9 (0.56), which was significantly higher than group $1(0.80(0.31))$. Similarly, the mean systolic:diastolic (S/D) ratio was also significantly higher in group 2 , i.e. 5.02 v. 1.99 in group $1(p<0.001)$.

There were $36(55.4 \%)$ preterm deliveries ( $<37$ weeks) in group 2 v. $24(36.9 \%)$ in group $1(p=0.054)$. Term deliveries ( $\geq 37$ weeks) were more in group $1(63.0 \%)$ than in group $2(47.0 \%)$. There were six intrauterine deaths in group 2 . Vaginal delivery was more

Table 1. Study group characteristics

\begin{tabular}{|c|c|c|c|}
\hline Characteristics & $\begin{array}{l}\text { Group } 1 \\
(n=65), \\
n(\%)^{*}\end{array}$ & $\begin{array}{l}\text { Group } 2 \\
(n=65), \\
n(\%)^{*}\end{array}$ & $p$-value \\
\hline Age (years), mean (SD) & $23.89(2.38)$ & $23.42(2.22)$ & 0.240 \\
\hline Parity, mean (SD) & $1.68(0.86)$ & $1.65(0.84)$ & 0.837 \\
\hline $\begin{array}{l}\text { Body mass index }\left(\mathrm{kg} / \mathrm{m}^{2}\right) \text {, } \\
\text { mean }(\mathrm{SD})\end{array}$ & $22.4(2.29)$ & $22.32(1.88)$ & 0.856 \\
\hline $\begin{array}{l}\text { Mean arterial blood pressure } \\
(\mathrm{mmHg}) \text {, mean (SD) }\end{array}$ & $84.2(3.30)$ & $81.3(2.60)$ & 0.765 \\
\hline \multicolumn{4}{|l|}{ Maternal characteristics } \\
\hline $\begin{array}{l}\text { Pregnancy-induced } \\
\text { hypertension }\end{array}$ & $16(24.60)$ & $16(24.60)$ & \\
\hline Gestational hypertension & $11(16.92)$ & $4(6.15)$ & 0.097 \\
\hline Pre-eclampsia & $4(6.15)$ & $9(13.84)$ & 0.241 \\
\hline Eclampsia & $1(1.53)$ & $3(4.61)$ & 0.619 \\
\hline \multicolumn{4}{|l|}{$\begin{array}{l}\text { Ultrasound findings, mean } \\
\text { (SD) }\end{array}$} \\
\hline $\begin{array}{l}\text { Abdominal } \\
\text { circumference (weeks) }\end{array}$ & $31.48(1.90)$ & $30.01(2.33)$ & $<0.001$ \\
\hline Estimated fetal weight $(\mathrm{kg})$ & $1.96(0.27)$ & $1.67(0.32)$ & $<0.001$ \\
\hline \multicolumn{4}{|l|}{ UA Doppler findings } \\
\hline Systolic:diastolic ratio & $1.99(0.38)$ & $5.02(1.87)$ & $<0.001$ \\
\hline PI & $0.80(0.31)$ & $1.90(0.56)$ & $<0.001$ \\
\hline \multicolumn{4}{|l|}{ Abnormal doppler findings } \\
\hline $\begin{array}{l}\text { Reduced end diastolic flow } \\
\text { (PI >95th percentile) }\end{array}$ & - & $36(55.40)$ & - \\
\hline AEDF & - & $16(24.60)$ & - \\
\hline REDF & - & $13(20.00)$ & - \\
\hline
\end{tabular}


commonly seen in group $1(n=56 ; 86.20 \%)$ v. group $2(n=29$; $44.60 \%)$. Among the subjects in group 2,55.40\% $(n=36)$ underwent caesarean deliveries, compared with $13.80 \%(n=9)$ in group 1 $(p<0.001)$. Group 2 had a significantly lower mean (SD) birth weight of $1.59(0.40) \mathrm{kg} \mathrm{v} .1 .87(0.23) \mathrm{kg}$ for group $1(p<0.001)$ (Table 2$)$.
Considerably higher neonatal intensive care unit (NICU) mortality was seen in $30.50 \%$ of babies in group 2, compared with the $6.70 \%$ observed in group $1(p<0.001)$.

The placental histopathological findings are detailed in Table 3. A significantly lower mean (SD) placental weight in group 2

Table 2. Neonatal outcomes of study population

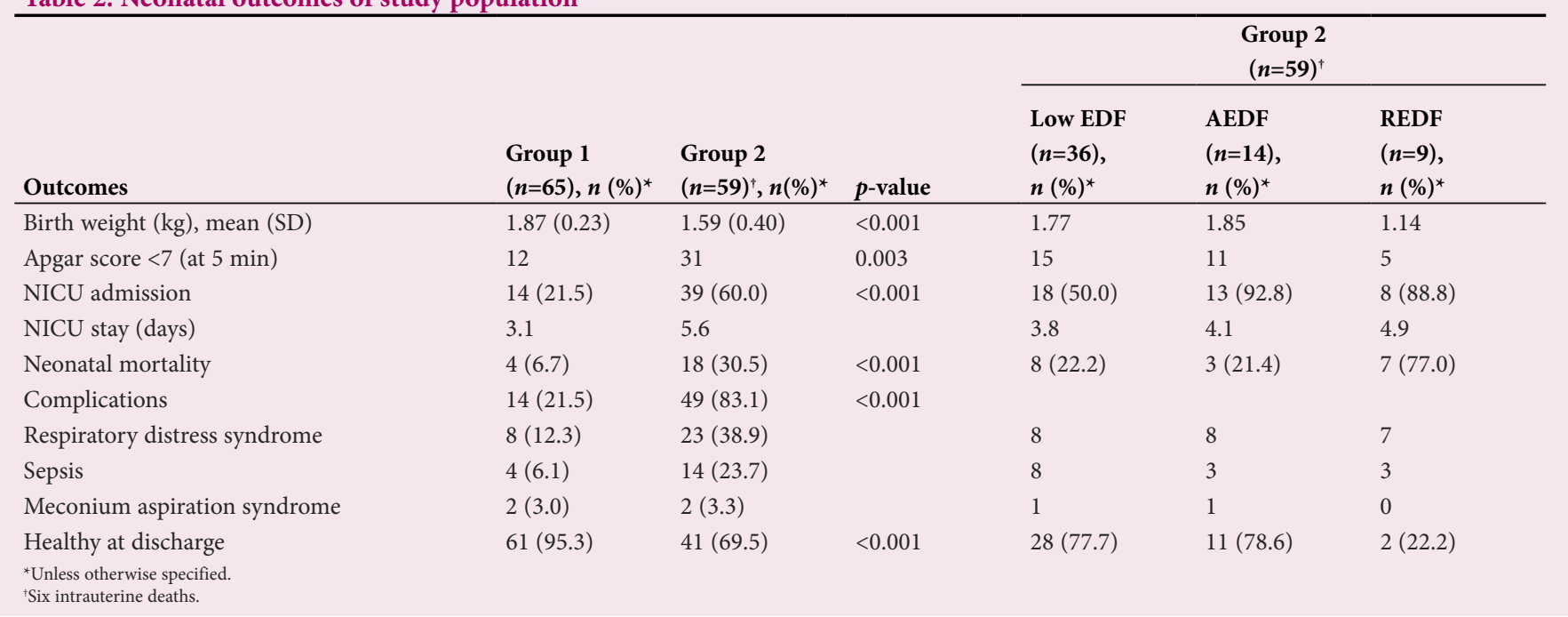

Table 3. Comparison of placental histopathological findings in normal (group 1) and abnormal (group 2) Doppler group (N=130)

\begin{tabular}{|c|c|c|c|c|c|c|}
\hline \multirow[b]{2}{*}{ Outcomes } & \multirow[b]{2}{*}{$\begin{array}{l}\text { Group } 1 \\
(n=65), n(\%)^{*}\end{array}$} & \multirow[b]{2}{*}{$\begin{array}{l}\text { Group } 2 \\
(n=65), n(\%)^{*}\end{array}$} & \multirow[b]{2}{*}{$p$-value } & \multicolumn{3}{|c|}{$\begin{array}{c}\text { Group } 2 \\
(n=65)\end{array}$} \\
\hline & & & & $\begin{array}{l}\text { Low EDF } \\
(n=36)\end{array}$ & $\begin{array}{l}\text { AEDF } \\
(n=16)\end{array}$ & $\begin{array}{l}\text { REDF } \\
(n=13)\end{array}$ \\
\hline Placental weight $(\mathrm{g})$, mean (SD) & $311.6(67.5)$ & $228.9(77.5)$ & $<0.001$ & - & - & - \\
\hline \multicolumn{7}{|l|}{ Gross examination } \\
\hline Haemorrhage & $8(12.30)$ & $19(29.20)$ & 0.100 & - & - & - \\
\hline Calcification & $13(20.00)$ & $44(67.70)$ & $<0.001$ & - & - & - \\
\hline \multicolumn{7}{|l|}{ Microscopic examination } \\
\hline Villous infarction & 0 & $13(20.00)$ & $<0.001$ & 8 & 2 & 3 \\
\hline Agglutination & $4(6.15)$ & $36(55.38)$ & $<0.001$ & 21 & 8 & 7 \\
\hline ST knots & & & 0.003 & & & \\
\hline$<20 \%$ & $51(78.46)$ & $36(55.38)$ & & 18 & 8 & 10 \\
\hline \multicolumn{7}{|l|}{ MUP } \\
\hline Intervillous fibrin deposition & $4(6.15)$ & $38(58.46)$ & $<0.001$ & 21 & 9 & 8 \\
\hline Perivillous fibrin deposition & $2(3.08)$ & $2(3.08)$ & 1 & 2 & 0 & 0 \\
\hline Villous hypoplasia & 0 & $2(3.08)$ & 0.496 & 0 & 1 & 1 \\
\hline Intervillous haematoma & 0 & $1(1.53)$ & 1 & 1 & 0 & 0 \\
\hline Retroplacental haematoma & $1(1.53)$ & $6(9.23)$ & 0.115 & 5 & 1 & 0 \\
\hline \multicolumn{7}{|l|}{$\begin{array}{l}\text { Fetal underperfusion } \\
\text { (FUP) }\end{array}$} \\
\hline Fetal vasculopathy & $1(1.53)$ & $2(3.08)$ & 1 & 0 & 1 & 1 \\
\hline Avascular villi & $3(4.60)$ & $5(7.70)$ & 0.718 & 2 & 2 & 1 \\
\hline \multicolumn{7}{|l|}{ Inflammatory lesions } \\
\hline Villitis & $1(1.53)$ & $3(4.61)$ & 0.619 & 3 & 0 & 0 \\
\hline Chorioamnionitis & $5(7.69)$ & $9(13.84)$ & 0.258 & 8 & 1 & 0 \\
\hline Vasculitis & $1(1.53)$ & $6(9.23)$ & 0.115 & 0 & 0 & 0 \\
\hline Calcification & $26(40.00)$ & $46(70.00)$ & 0.001 & 0 & 0 & 0 \\
\hline$<10 \%$ & $19(29.23)$ & $28(43.08)$ & - & 15 & 6 & 7 \\
\hline$>10 \%$ & 7 (10.77) & $18(27.69)$ & - & 15 & 1 & 2 \\
\hline
\end{tabular}


(228.9 (77.5) g) was found compared with group 1 (311.6 (67.5) g). On gross examination, areas of necrosis and calcification were present in significantly higher numbers in the placentas of group 2 compared with those of group 1 ( $p=0.007$ and $p<0.001$, respectively). Among the lesions signifying MUP, four were found to occur significantly more in the placentas of group 2 . These were villous infarction $(20 \%$ v. $0 \%)$, villous agglutination $(55.38 \%$ v. $6.20 \%)$, intervillous fibrin deposition (55.4\% vs $6.1 \%)$ and ST knots (30.77\% v. 7.69\%). Among the others histopathological category, stromal fibrosis and calcification were significantly higher in group 2. No significant difference was seen between lesions of fetal vascular underperfusion (FUP) and lesions of inflammatory origin.

An ROC curve based on the above 6 placental lesions (4 MUP and 2 others) was plotted and the best cut-off point was found to be $\geq 3$ placental lesions (Youden Index), which was used as criteria for our study (Table 4 and Fig. 2). The area under the curve (AUC) was 0.898 (95\% CI 0.842 - 0.955). There was a total of 57 patients in our study with abnormal placental pathology. Fifty-two patients in group 2 had placental pathologies listed above compared with just five patients in group $1(p<0.001)$. Further, based on the ROC curve, abnormal Doppler (reduced flow, AEDF or REDF) had a sensitivity of $80 \%$ and specificity of $92.3 \%$ as a test for detection of abnormal placental pathology (placental lesions $\geq 3$ ) in SGA pregnancies.

Table 4. Distribution of significant placental histopathological lesions between groups 1 and 2

\begin{tabular}{llllllll}
\hline & \multicolumn{7}{c}{ Number of significant histopathological lesions } \\
\cline { 2 - 8 } & $\mathbf{0}$ & $\mathbf{1}$ & $\mathbf{2}$ & $\mathbf{3}$ & $\mathbf{4}$ & $\mathbf{5}$ & $\mathbf{6}$ \\
\hline Group 1 & 7 & 30 & 23 & 4 & 1 & 0 & 0 \\
Group 2 & 1 & 3 & 9 & 27 & 18 & 4 & 3 \\
Total & 8 & 33 & 32 & 31 & 19 & 4 & 3
\end{tabular}

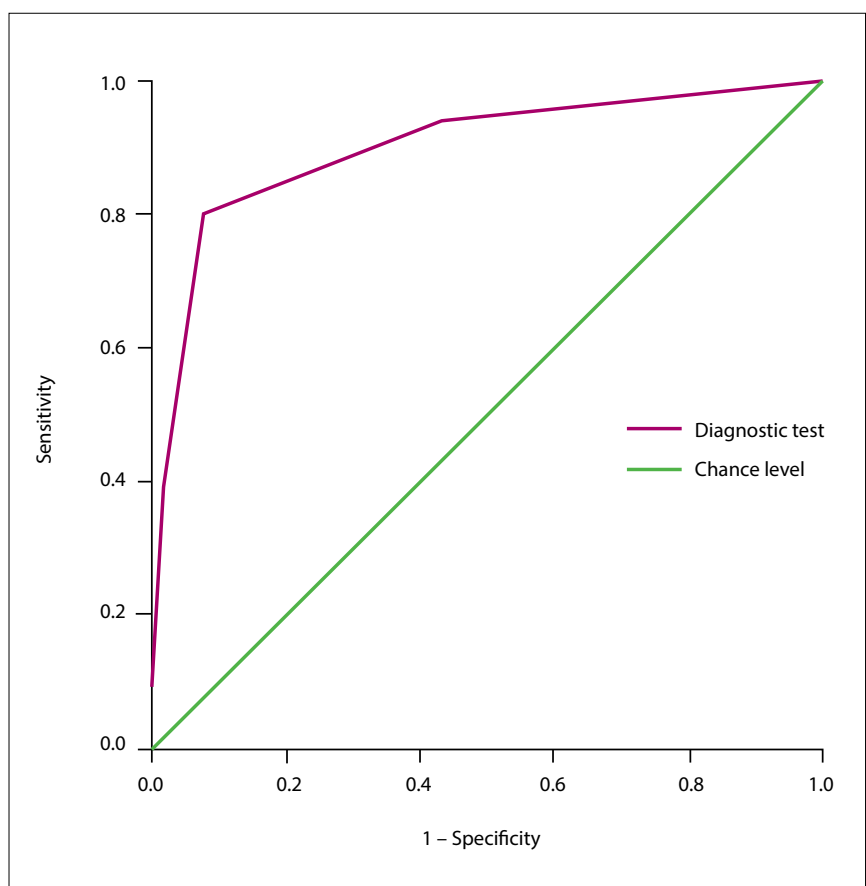

Fig. 2. ROC curve for six placental lesions. The area under the curve was 0.898 at $95 \%$ CI $0.84-0.96$. The optimal threshold point for the lesions was obtained where the sum of sensitivity and specificity was at a maximum (Youden Index) and the best cut-off point was found to $b e \geq 3$ placental lesions.

\section{Discussion}

FGR is still a significant problem despite extensive research into its aetiology, pathogenesis and management. ${ }^{[8]}$ Abnormal UA DV in pregnancies complicated by FGR has been associated with a heterogeneous, nonspecific group of histological lesions of the placenta irrespective of gestational age or FGR aetiology. ${ }^{[2,6,10-14]}$ The exact pathophysiological mechanisms correlating these are not well characterised. ${ }^{[15]}$ Various authors have used different placental histopathological classifications, categorisations of placental lesions, Doppler indices and statistical methods making interpretation and inter-study comparison difficult. ${ }^{[2,6,10-14]}$

Dicke et al. ${ }^{[11]}$ retrospectively investigated the screening efficacy of UA S/D, PI, and AEDF for adverse pregnancy outcomes and placental abnormalities in SGA fetuses. Ninety-four percent of cases with either an S/D or a PI above the 95th percentile, or AEDF, had evidence of placental pathology. They found a higher number of MUP lesions where there was an abnormal Doppler (50\%) compared with a normal Doppler (27.6\%). Fetal vascular obstructive lesions were lower than MUP lesions, i.e. $27 \%$ in group 2 v. $14.9 \%$ in group 1. They concluded that abnormal Doppler indices predicted placental lesions. The screening UA Doppler parameters for placental abnormalities in their study had a sensitivity of $42.1 \%$ and specificity of $89.3 \%$.

We based our analysis on the robust placental classification provided by Redline. ${ }^{[9]}$ In our study, out of the 15 placental lesions investigated, significant differences were noted for 6 placental lesions in the two DV groups (Table 3). These findings supported abnormal utero-placental circulation especially of maternal aetiology. Many other studies have similarly pointed towards a predominant MUP origin for FGR. ${ }^{[6,10,11]}$ Our study derived a much higher sensitivity (80\%) and specificity (92.3\%) for abnormal Doppler (reduced flow, AEDF or REDF) as a screening tool for detection of abnormal placental pathology.

Vedmedovska et al. ${ }^{[6]}$ found major placental microscopic lesions in 50 women with prenatally suspected, and post-delivery confirmed, FGR. They found $56.6 \%$ subjects with abnormal DV having $>4$ placental lesions compared with $25 \%$ in the normal Doppler group ( $p=0.003$ ). The percentage of villous infarction was $48.3 \%$ v. $25 \%$, intervillous haematoma $65.5 \%$ v. $35 \%$, thickening of the basement membrane $58.6 \%$ v. $45 \%$, perivillous fibrin deposition $86.2 \%$ v. $80 \%$, stromal fibrosis $37.9 \%$ v. $10 \%$ in the abnormal v. normal Doppler group. Compared with the control group with normal Doppler, FGR women with abnormal DV had more villous infarctions $(p=0.0003)$, and intervillous thrombi $(p<0.0001)$. Thickening of the basal membrane and villitis were also linked to FGR. In our study abnormal Doppler FGR had significantly higher numbers of villous infarction, a marker of MUP. Moreover, the optimal threshold for classification of abnormal placental pathology was detected at $\geq 3$ placental lesions, similar to the aforementioned study by Vedmedovska et al. ${ }^{[6]}$

Spinillo et al. ${ }^{[10]}$ followed 126 FGR pregnancies for defined placental lesions and correlated findings with UA Doppler velocimetry. They found the PI to be normal in 45 (35.7\%) and increased in 44 (34.9\%) of the women. End-diastolic UA Doppler flow was absent in 27 (21.4\%) and reversed in 10 (7.9\%) cases. Increased placental intervillous fibrin deposits, villous hypoplasia, ST knots, giant cells, and immature intermediate trophoblasts were directly related to worsening of UA Doppler results. They also found villous hypoplasia ( $p=0.031)$, trophoblast giant cell $(p=0.015)$, 
and immature intermediate trophoblasts $(p=0.014)$ directly related to worsening of UA Doppler measurements, a finding that was not replicated in our study. Another significant difference was a higher frequency of villous agglutination $(p=0.001)$ in abnormal Doppler subjects in our study compared with theirs ( $p=0.096$ ).

In a more recent study by Parra-Saavedra et al, ${ }^{[12]} 126$ fetuses with normal UA Doppler indices that were delivered after 34 weeks' gestation were studied. Among 97 histological findings consistent with placental underperfusion in 84 SGA pregnancies, maternal vascular supply placental injuries were far more in number (79.4\%) when compared with fetal vascular supply placental lesions (20.6\%). The authors concluded that the presence of histological signs of placental underperfusion implies a poorer neonatal outcome. In our study too, the rate of preterm deliveries, neonatal complications and NICU stay was more pronounced in group 2 with abnormal DV (Table 3).

There are many limitations of our study, which we acknowledge. We evaluated only UA indices. Uterine artery, middle cerebral artery and ductus venosus Doppler, which has been evaluated by many others, were not utilised in our investigations. ${ }^{[12,14]}$ Only UA Doppler PI values were used for comparison with placental lesions. The S/D ratio and Resistance Index, although studied, were not used for final analysis; however, the study had a prospective study design and matched SGA subjects for both normal and abnormal Doppler findings. The histopathological blinding and controlled Doppler group ensured precise and unbiased results. The clustering of specific placental lesions into the abnormal Doppler group raised support for MUP as the main aetiology for FGR. The UA Doppler has good screening ability, with a sensitivity of $80 \%$ and a specificity of $92.3 \%$, for detection of MUP placental lesions as inferred from our study, making it a potential tool to identify FGR and in turn improve perinatal outcomes through intensive sonographic fetal surveillance and more favourable timing of delivery. The poorer neonatal outcome reported with abnormal Doppler indices/MUP lesions calls for even more stringent clinical supervision of these lesions.

\section{Conclusion}

There was a higher number of MUP placental histopathological lesions in FGR patients with abnormal Doppler findings supporting a maternal aetiology for FGR. With abnormal placental pathology defined as $n \geq 3$ placental lesions, these abnormal Doppler findings had a sensitivity of $80.0 \%$ and a specificity of $92.3 \%$ for predicting abnormal placental pathology in SGA. Furthermore, the abnormal Doppler group had a significantly higher neonatal morbidity.

Conflict of interest. The authors declare that they have no conflict of interest.

1. Macara L, Kingdom JCP, Kohnen G, Bowman AW, Greer IA, Kaufman P. Elaboration of stem villus vessels in growth restricted pregnancies with abnormal umbilical artery Doppler waveforms. Br J Obstet Gynaecol 1995;102(10):807-812. https://doi.org/10.1111/j.1471-0528.1995.tb10847.x

2. Macara L, Kingdom JCP, Kaufmann P, et al. Structural analysis of placental terminal villi from growth-restricted pregnancies with abnormal umbilical artery Doppler waveforms. Placenta 1996;17(1):37-48. https://doi.org/10.1016/s0143-4004(05)80642-3

3. Sebire NJ, Goldin RD, Regan L. Histomorphological evidence for chronic vasoconstriction of placental stem vessels in pregnancies with intrauterine growth restriction and abnormal umbilical artery velocimetry indices. J Pathol 2001;195:19A.

4. Apel-Sarid L, Levy A, Holcberg G, Sheiner E. Term and preterm $(<34$ and $<37$ weeks gestation) placental pathologies associated with fetal growth restriction. Arch Gynecol Obstet 2010;282(5):487-492. https://doi.org/10.1007/s00404-009-1255-1

5. Tomas SZ, Roje D, Prusac IK, Tadin I, Capkun V. Morphological characteristics of placentas associated with idiopathic intrauterine growth retardation: A clinicopathologic study. Eur J Obstet Gynecol Reprod Biol 2010;152(1):39-43. https://doi.org/10.1016/j.ejogrb.2010.05.006

6. Vedmedovska N, Rezeberga D, Teibe U, Melderis I, Donders GG. Microscopic lesions of placenta and Doppler velocimetry related to fetal growth restriction. Arch Gynecol Obstet 2011;284(5):1087-1093. https://doi.org/10.1007/s00404-010-1781-x

7. Alexander GR, Himes JH, Kaufman RB, Mor J, Kogan M. A United States national reference for fetal growth. Obstet Gynecol 1996;87(2):163-168. https://doi.org/10.1016/0029-7844(95)00386-x

8. Lubchenco LO, Hansman C, Dressler M, Boyd E. Intrauterine growth as estimated from live born birth-weight data at 24 to 42 weeks of gestation. Pediatrics 1963:32:793-800.

9. Redline RW. Placental pathology: A systematic approach with clinical correlations. Placenta 2008;29(Suppl A):S86-91. https://doi.org/10.1016/j.placenta.2007.09.003

10. Spinillo A, Gardella B, Bariselli S, Alfei A, Silini E, Dal Bello B. Placental histopathologica correlates of umbilical artery Doppler velocimetry in pregnancies complicated by fetal growth restriction. Prenat Diagn 2012;32 (13):1263-1272. https://doi.org/10.1002/pd.3988

11. Dicke JM, Huettner P, Yan S, Odibo A, Kraus FT. Umbilical artery Doppler indices in smal for gestational age fetuses: Correlation with adverse outcomes and placental abnormalities. Ultrasound Med 2009;28(12):1603-1610. https://doi.org/10.7863/jum.2009.28.12.1603

12. Parra-Saavedra M, Crovetto F, Triunfo S, Savchev S, Peguero A, Nadal A. Placental findings in late-onset SGA births without Doppler signs of placental insufficiency. Placenta 2013;34(12):11361141. https://doi.org/10.1016/j.placenta.2013.09.018

13. Vedmedovska N, Rezeberga D, Teibe U, Melderis I, Donders GG. Placental pathology in fetal growth restriction. Eur J Obstet Gynecol Reprod Biol 2011;155(1):36-40. https://doi.org/10.1016/j. ejogrb.2010.11.017

14. Madazli R, Somunkiran A, Calay Z, Ilvan S, Aksu MF. Histomorphology of the placenta and the placental bed of growth restricted fetuses and correlation with the Doppler velocimetries of the uterine and umbilical arteries. Placenta 2003;24(5):510-516.

15. Sebire NJ. Umbilical artery Doppler revisited: Pathophysiology of changes in intrauterine growth restriction revealed. Ultrasound Obstet Gynecol 2003;21(5):419-422. https://doi.org/10.1002/ uog. 133 